\title{
Development and Characteristics of Anorthite-Based Traditional Ceramic Materials to Suppress Sintering Deformation
}

\author{
JungHoon Choi ${ }^{* * * *}$, UngSoo Kim***, and WooSeok Cho**; \\ *Department of Materials Engineering, Gyeongsang National University, Jinju 52828, Korea \\ ${ }^{* *}$ Ceramicware Center, Korea Institute of Ceramic Engineering and Technology, Icheon 17303, Korea
}

(Received September 29, 2016; Revised January 12, 2017; Accepted January 16, 2017)

\begin{abstract}
An anorthite-based traditional ceramic was developed by adding secondary flux materials to a mixture of kaolin and $\mathrm{CaCO}_{3}$ in order to minimize the deformation during the sintering process. Three flux materials, feldspar, talc, and frit, were evaluated by comparison with two commercial chinaware bodies. Anorthite body with glass frit exhibited poor firing shrinkage. Poor mechanical properties (modulus of rupture, MOR $<30 \mathrm{MPa}$ ) was observed for the bodies with feldspar. Another anorthite body was formulated with wollastonite as a Ca source. The fired body showed a MOR of $81 \mathrm{MPa}$ and a shrinkage rate of $6 \%$ when wollastonite was added up to $50 \%$. In the XRD analysis, the phase ratio between anorthite and quartz was the highest in the specimen with $50 \%$ wollastonite addition. Homogeneous and relatively small closed pores were observed in the microstructural analysis. These results suggest that a ceramic body formulated with $50 \%$ kaolin and $50 \%$ wollastonite can be fired at $1200^{\circ} \mathrm{C}$ with a $6 \%$ firing shrinkage rate, giving rise to minimal sintering deformation.
\end{abstract}

Key words : Anorthite, Raw material, Low Pyro-Plasticty, Shrinkage

\section{Introduction}

S intering is a feature inherent to the manufacturing process of ceramics. Ceramic materials undergo crystallization through a sintering process and come to have material properties inherent to ceramics. For most of the traditional ceramic materials, wet sintering with the generation of a vitreous phase is realized. ${ }^{1,2)}$ Upon entering the sintering temperature band with the formation of a liquid phase, abnormal deformation due to gravity occurs. Such deformation is manifested in various ways depending on the shapes, thicknesses, etc. of the green body, and an accurate prediction of the sintering deformation in advance is not possible due to frequent property changes of the natural raw materials and inhomogeneity of the manufacturing processes. Therefore, the efforts to suppress the defects caused by sintering deformation in the development of traditional ceramics products depend on experiential data, and act as a factor for increasing the required resources having unique malformation. In the manufacturing process for traditional ceramics, there has been strong demand for materials capable of suppressing the deformation to overcome the sintering deformation that acts as a major obstacle to new design development. which has been responded by designing additional reinforcing structures or forming thicknesses of the malformation to be different in the gravity direction. How-

${ }^{\dagger}$ Corresponding author: WooSeok Cho

E-mail : wscho@kicet.re.kr

Tel : +82-31-645-1405 Fax : +82-31-645-1440 ever, scientific approaches to a series of studies for effective reduction of deformation in the materials themselves have been relatively alienated as compared with other studies due to the diversity of china compositions and the low added value of china products.

In the present study, experiments and analyses have been conducted on the development and the characteristics of small-deformation traditional ceramics utilizing natural minerals in conformity with the aforementioned demand. To effectively suppress the sintering deformation, materials having an anorthite crystal phase have been studied by varying the type and the amount of sintering aids, which promote sintering at low temperatures while retaining similar properties to those of the existing materials.

\section{Experimental Procedure}

Irregular sintering deformation of traditional ceramic materials can reduce scatter in the sintering deformation by inducing a low shrinkage rate. For this purpose, the sintering temperature, the key factor for variation in shrinkage rates, was lowered, and research and development were conducted for materials retaining a strength approximating that of the traditional ceramic materials distributed in the market. With kaolin $\left(\mathrm{Al}_{2} \mathrm{O}_{3} \cdot 2 \mathrm{SiO}_{2} \cdot 2 \mathrm{H}_{2} \mathrm{O}\right)$ and calcite $\left(\mathrm{CaCO}_{3}\right)^{3)}$ as the basic compositions, the materials forming anorthite $(\mathrm{CaO}$. $\mathrm{Al}_{2} \mathrm{O} \cdot 2 \mathrm{SiO}_{2}$ ) crystal phase at $1200^{\circ} \mathrm{C}$ were studied through experiments. ${ }^{4}$ As the sintering aids, $\mathrm{CaCO}_{3}$ (Daejung Chem. Co., 99\%), feldspar, talc, frit ${ }^{5)}$ (Ferro Frit 3134), and Wollastonite $\left(\mathrm{CaSiO}_{3}\right)$ were employed. Shrinkage rates and 
strengths were analyzed as a function of the difference in individual sintering aids and three sintering temperatures, $1100^{\circ} \mathrm{C}, 1200^{\circ} \mathrm{C}$, and $1250^{\circ} \mathrm{C}{ }^{6}{ }^{6}$ By first selecting the condition that yielded a relatively low shrinkage rate, the results as a function of mixing ratios for the sintering aids at temperatures of $1000^{\circ} \mathrm{C}, 1100^{\circ} \mathrm{C}$, and $1200^{\circ} \mathrm{C}$ were additionally analyzed. For the mixing ratios, the added minerals were increased by increments of $10 \%$ up to $30 \sim 50 \%$ through calculation of the molar ratios that are advantageous to the formation of the anorthite $\left(\mathrm{CaAl}_{2} \mathrm{Si}_{2} \mathrm{O}_{8}\right)$ crystal phase. ${ }^{7,8)}$ When more than $50 \%$ of sintering aids were added, the plasticity was drastically lowered and this was consequently excluded from the experimental conditions. Finally, the composition having the most desirable characteristics was selected, and the reasons for property changes were investigated through a microstructural analysis. The experimental procedures are shown in Fig. 1.

To ensure sufficient mixing of the raw materials, mixing and pulverization were carried out in a ball mill for $24 \mathrm{~h}$ using distilled water. ${ }^{9)}$ The materials mixed according to each experimental condition were pressurized and formed in a plaster mold of the specimen form. For the sintering process of the specimens, the temperature was raised at a rate of $5^{\circ} \mathrm{C}$ by using an electric furnace. In the case of sintering temperature, the maximum temperature upon sintering was shown, and the specimens were held at this temperature for $1 \mathrm{~h}$, followed by natural cooling. For each condition,

\begin{tabular}{|c|}
\hline Raw Material \\
\hline Kaolinite, $\mathrm{CaCO}_{3}$, Boric Acid, Feldspar, Talc, Frit, Wollastonite, $\mathrm{Al}_{2} \mathrm{O}_{3}, \mathrm{SiO}_{2}$ \\
\hline$\downarrow$ \\
\hline Mixing \& Milling \\
\hline $\begin{array}{l}\text { Wet Mixing in D.I Water for } 24 \mathrm{~h} \text { in Ball Mill } \\
\text { (Milling media : stabilized alumina ball) }\end{array}$ \\
\hline$\downarrow$ \\
\hline Pressure Casting \\
\hline $2.2 \mathrm{kgf} / \mathrm{Cm}^{2}$ in Gydsum mould \\
\hline$\downarrow$ \\
\hline Sintering \\
\hline $\begin{array}{l}1,000^{\circ} \mathrm{C}, 1,100^{\circ} \mathrm{C}, 1,200^{\circ} \mathrm{C} \\
\left(5^{\circ} \mathrm{C} / \mathrm{min} \text { in electric furnace }\right)\end{array}$ \\
\hline$\downarrow$ \\
\hline Characterization \\
\hline Microstructure, Mechanical strength, Shrinkage \\
\hline
\end{tabular}

Fig. 1. Flow chart of experimental process of Anorthitebased material for 3D Printing. analyses of shrinkage rate, density (Archimedes method), flexural strength (Microload System MOR tester, R\&B, Korea), and crystal phase (D/Max2500VL, Rigaku, Japan) were conducted. In addition, microstructures (JSM-6390, JEOL, Japan) were observed by polishing the cross sections after sintering.

\section{Results and Discussion}

Table 1 shows the mineral formulation ratios as a function of sintering aids for the manufacture of ceramic materials that form anorthite $\left(\mathrm{CaO} \cdot \mathrm{Al}_{2} \mathrm{O}_{3} \cdot 2 \mathrm{SiO}_{2}\right)$ crystal phase. Varying properties were analyzed by adding different sintering aids with Kaolinite fixed as the starting raw material. The conditions $\mathrm{F}$ and $\mathrm{G}$ represent the traditional ceramic materials distributed in the market.

To evaluate the shrinkage rates as a function of change in the sintering aids, the shrinkage rate results as a function of sintering temperature for each specimen are shown in Fig. 2. The specimen with feldspar added as the sintering aid and the specimen with the addition of wollastonite exhibited shrinkage rates less than $2 \%$, and thus conform well with the purpose of the present study. Commercial materials showed shrinkage rates higher than $10 \%$, affirming that the possibility of sintering deformation was the highest. In all specimens, the shrinkage rates were confirmed to increase in proportion to the rise in sintering tem-

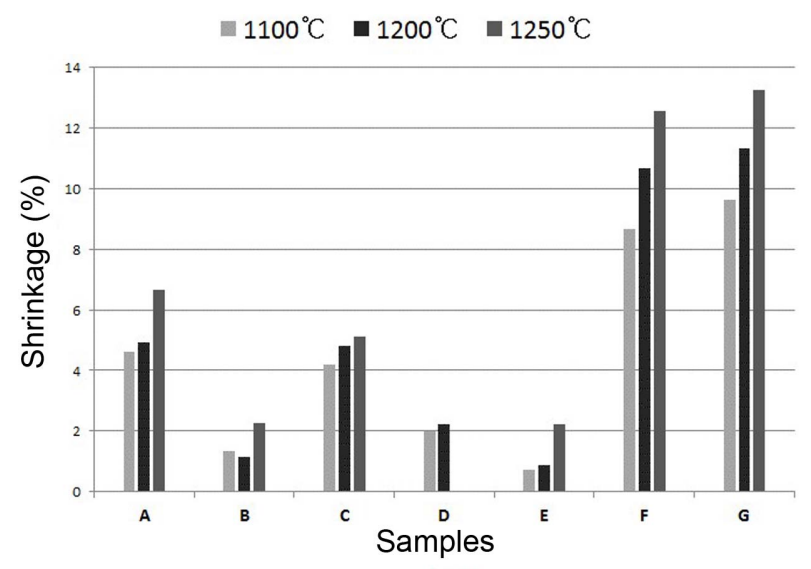

Fig. 2. Firing shrinkage of ceramic bodies with different sintering aids fired at 1100,1200 , and $1250^{\circ} \mathrm{C}$, respectively.

Table 1. Mineral Compositions with Different Sintering Aids

\begin{tabular}{ccccccc}
\hline Classification & Kaolin & Calcite & Feldspar & Frit & Talc & Wollastonite \\
\hline A & 72.0 & 28.0 & - & - & - & - \\
B & 50.5 & 19.5 & 30.0 & - & - & - \\
C & 68.5 & 26.5 & - & - & 20.0 & - \\
D & 57.7 & 22.3 & - & - & - & 30.0 \\
E & 70.0 & - & - & & \\
F & & Commercial traditional ceramic material from Company A & \\
G & & Commercial traditional ceramic material from Company B & \\
\hline
\end{tabular}




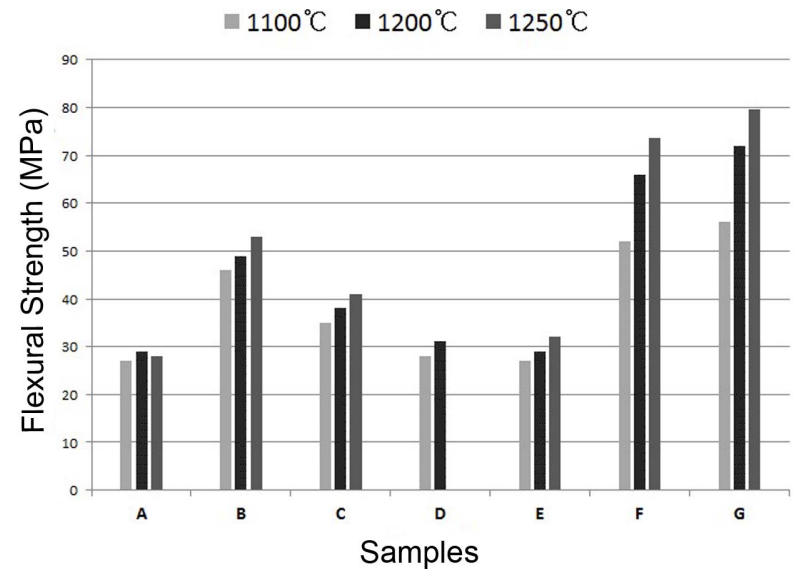

Fig. 3. Flexural strength of ceramic bodies with different sintering aids fired at 1100,1200 , and $1250^{\circ} \mathrm{C}$, respectively.

perature. The specimens using Talc as the sintering aid showed an increase in the shrinkage rates up to $1200^{\circ} \mathrm{C}$, melted failing to maintain the shape upon sintering at $1250^{\circ} \mathrm{C}$ so that measurements were disabled.

Strengths as a function of the change in sintering aids is shown in Fig. 3. Most specimens show a tendency of increasing strength a whole with an increase in temperature. In the specimen with Talc employed as a sintering aid, the strength increased up to $1200^{\circ} \mathrm{C}$. However, the overall strength shows a poor trend as compared with that of commercial materials. Different addition ratios of sintering aids to promote the strength of specimens B \& E, which showed low shrinkage rates, were analyzed. For the addition ratio of the sintering aid, the molar ratio was calculated so as to be advantageous to the formation of the anorthite crystal phase. $^{10)}$

\subsection{Sintered body of kaolinite + calcite + feldspar}

Table 2 shows the added amounts of feldspar. Material properties were analyzed by preparing three types of specimens with variation of the added amounts of feldspar. As shown in Fig. 4, it can be seen that all specimens have similar densities irrespective of the amounts of feldspar when the sintering temperature becomes $1200^{\circ} \mathrm{C}$. While the density shows a decreasing tendency with an increase in sintering temperature when feldspar was added up to $40 \%$, the density shows an increasing tendency for larger added amounts. However, overall densities of all specimens tend

Table 2. Ceramic Body Compositions Formulated with Kaolin, Calcite and Feldspar

\begin{tabular}{cccc}
\hline (w/o) & Kaolin & Calcite & Feldspar \\
\hline F-1 & 50.5 & 19.5 & 30.0 \\
F-2 & 43.2 & 16.8 & 40.0 \\
F-3 & 36.0 & 14.0 & 50.0 \\
\hline
\end{tabular}

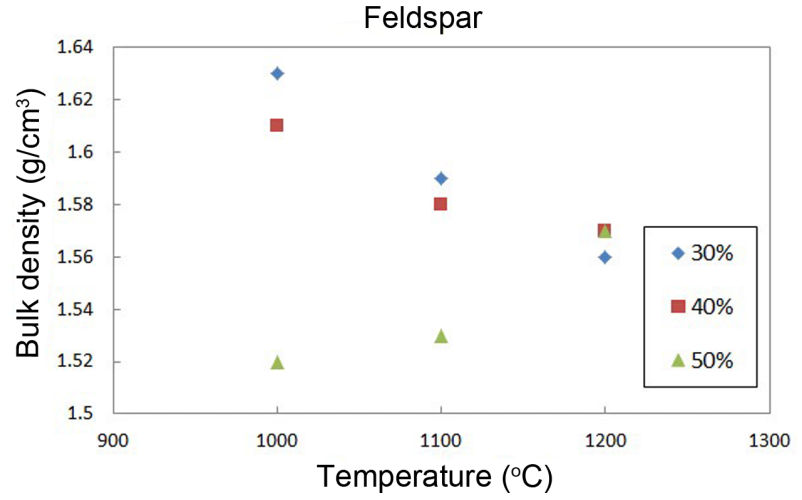

Fig. 4. Bulk density of ceramic bodies with addition of feldspar fired at 1000,1100 , and $1200^{\circ} \mathrm{C}$.

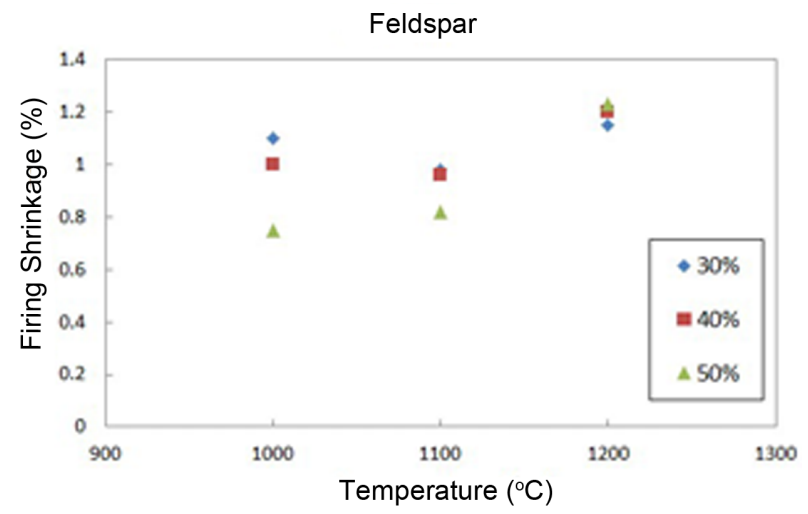

Fig. 5. Firing shrinkage of ceramic bodies with addition of feldspar fired at 1000,1100 , and $1200^{\circ} \mathrm{C}$.

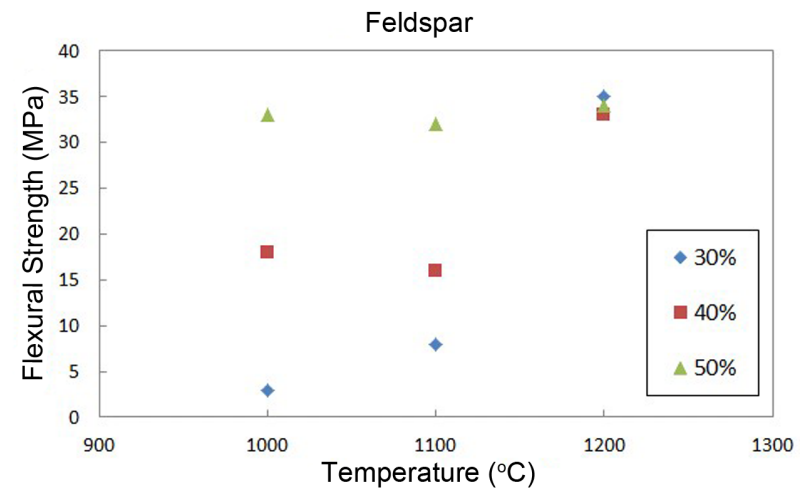

Fig. 6. Flexural strength of ceramic bodies with addition of feldspar fired at 1000,1100 , and $1200^{\circ} \mathrm{C}$.

to be low.

Shrinkage rates are shown in Fig. 5 . As can be seen in the graph, a low shrinkage rate of less than $2 \%$ can be affirmed. Fig. 6 shows the change in flexural strengths of the body as a function of the change in sintering temperature. As shown in the figure, the flexural strength increased with an increase in sintering temperature as a whole. However, when $1200^{\circ} \mathrm{C}$ is reached, all flexural strengths are confirmed to be similar, showing lower strengths as compared with those of commercial materials. 


\subsection{Sintered body of kaolinite+wollastonite}

Table 3 shows the added amounts of wollastonite. As shown in Fig. 7, the density increased with an increase in the added amounts of wollastonite. When the added amount of wollastonite reaches $50 \%$, the density exceeds the level of commercial materials of $\% 2.3 \mathrm{~g} / \mathrm{cm}^{3}$ and reaches $2.5 \mathrm{~g} / \mathrm{cm}^{3}$.

Figure 8 shows the change in the shrinkage rates as a function of the added amount and the sintering temperature. The shrinkage rate can be confirmed to be increased with an increase in the sintering temperature. However, low shrinkage rates in the range of $6 \%$ were observed as compared with commercial materials.

Figure 9 shows a change in the flexural strengths, where the strength of wollastonite is maintained at about $\sim 30$ $\mathrm{MPa}$ up to addition of $40 \%$, and dramatically increased to more than $80 \mathrm{MPa}$ upon $50 \%$ addition.

Table 3. Ceramic Body Compositions Formulated with Kaolin and Wollastonite

\begin{tabular}{ccc}
\hline (w/o) & Kaolin & Wollastonite \\
\hline W-1 & 70 & 30 \\
W-2 & 60 & 40 \\
W-3 & 50 & 50 \\
\hline
\end{tabular}

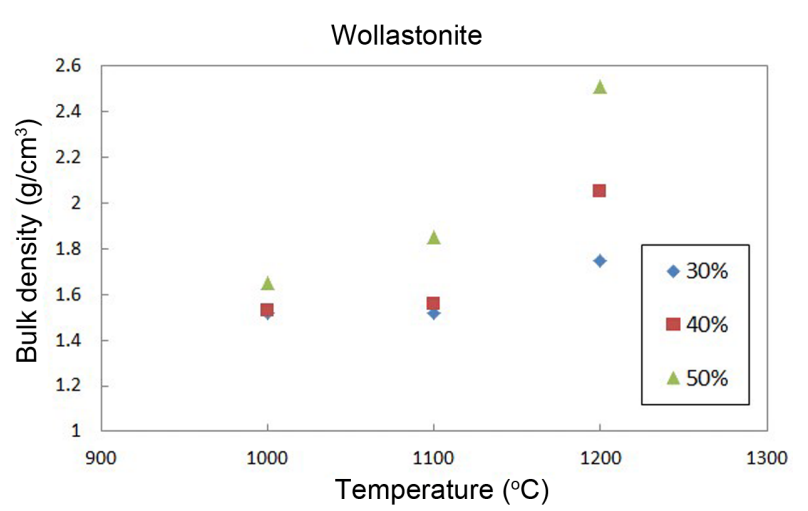

Fig. 7. Bulk density of ceramic bodies with addition of wollastonite fired at 1000,1100 , and $1200^{\circ} \mathrm{C}$.

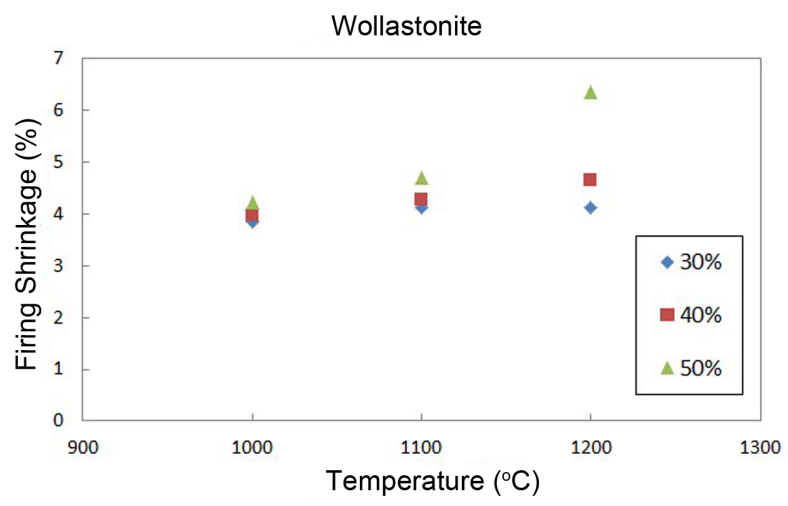

Fig. 8. Firing shrinkage of ceramic bodies with addition of wollastonite fired at 1000,1100 , and $1200^{\circ} \mathrm{C}$

\subsection{Microstructural analysis of anorthite-based ceramic material}

Microstructures of the specimens sintered at $1200^{\circ} \mathrm{C}$ were comparatively analyzed where the strengths and the density scatters were reduced with significant amounts of change in the composition analysis results observed with the addition of feldspar and wollastonite as sintering aids. Fig. 10 shows the change in the crystal phases of the body as a function of wollastonite addition. As shown in the figure, anorthite phase is observed as the main phase, and quartz phase as the second phase for all added amounts of wollastonite. However, as the added amounts of wollastonite are increased, the fraction of anorthite as the main phase increases relatively compared with the quartz phase, and quartz as the second phase is almost not observed under the condition of $50 \%$ wollastonite. Such result can be affirmed to cause the best characteristics to be observed previously as the fraction of Anorthite phase is increased when the strength as a function of the added amount of wollastonite is $50 \%$.

On the other hand, Fig. 11 shows the crystal structures as a function of the added amounts of feldspar. As the added amounts are increased or decreased, the main phase is changed from quartz phase to anorthite phase with the fraction of anorthite phase being relatively increased. However,

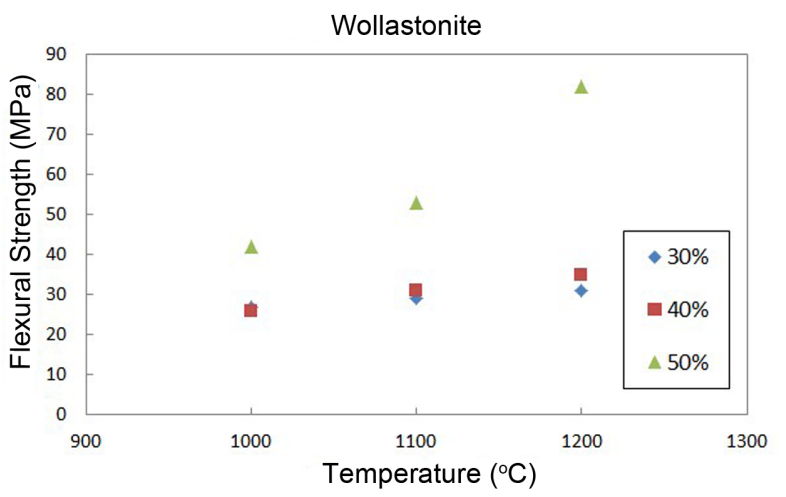

Fig. 9. Flexural strength of ceramic bodies with addition of wollastonite fired at 1000,1100 , and $1200^{\circ} \mathrm{C}$.

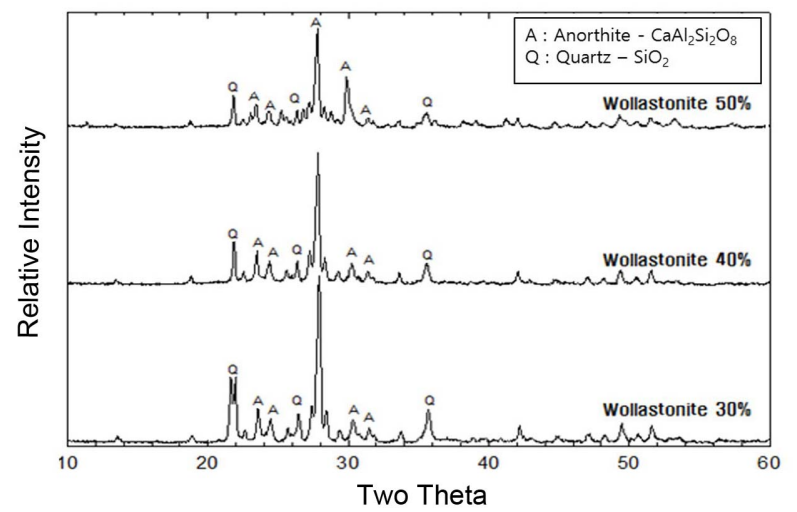

Fig. 10. XRD patterns for the ceramic bodies with variation in wollastonite content fired at $1200^{\circ} \mathrm{C}$ 


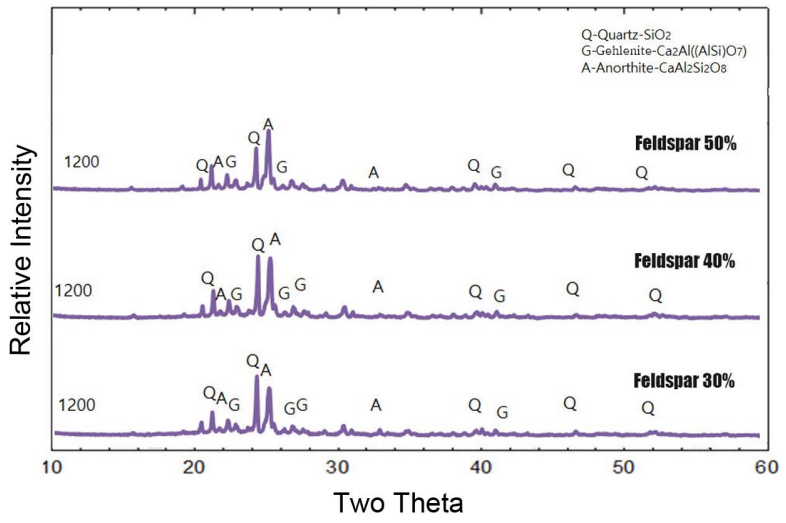

Fig. 11. XRD patterns for the ceramic bodies with variation in feldspar content fired at $1200^{\circ} \mathrm{C}$.

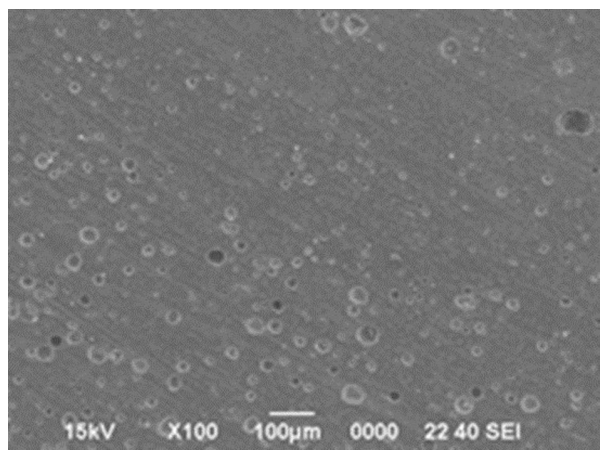

Fig. 12. Micrograph of the ceramic body with $50 \%$ wollastonite fired at $1200^{\circ} \mathrm{C}$

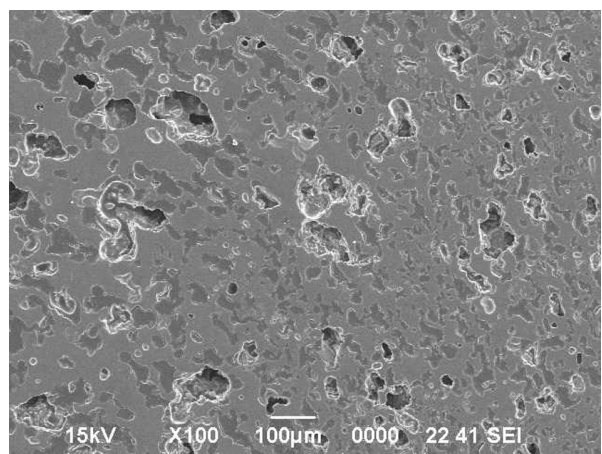

Fig. 13. Micrograph of the ceramic body with $50 \%$ feldspar fired at $1200^{\circ} \mathrm{C}$.

the amount of increase is insufficient and consequently the second phase of quartz and the third phase of gehlenite are still observed even with addition up to 50\%. It is confirmed that is the cause of the insignificant increase in strength observed previously despite an increase in the added amounts of feldspar.

Figure 12 shows a micrograph for the specimen with the body containing $50 \%$. Wollastonite was fired at $1200^{\circ} \mathrm{C}$. Small closed pores are uniformly distributed. On the other hand, Fig. 13 shows a micrograph for the sintered body with the addition of $50 \%$ of feldspar. Pores are huge and have an inhomogeneous distribution.

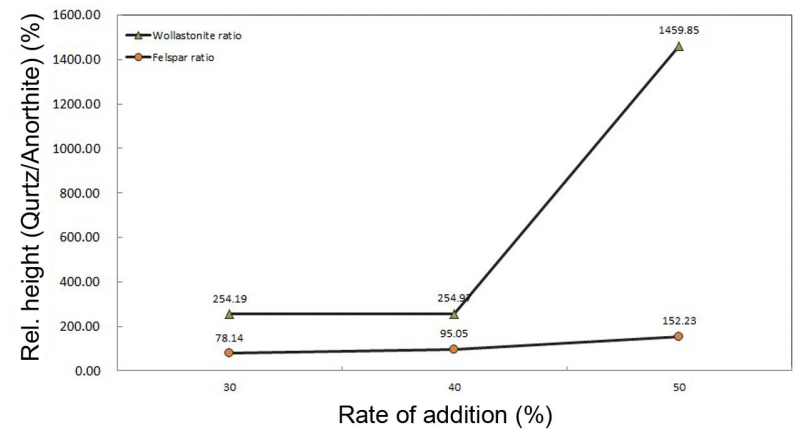

Fig. 14. Relative height ratio in XRD patterns. (quartz/anorthite)(\%).

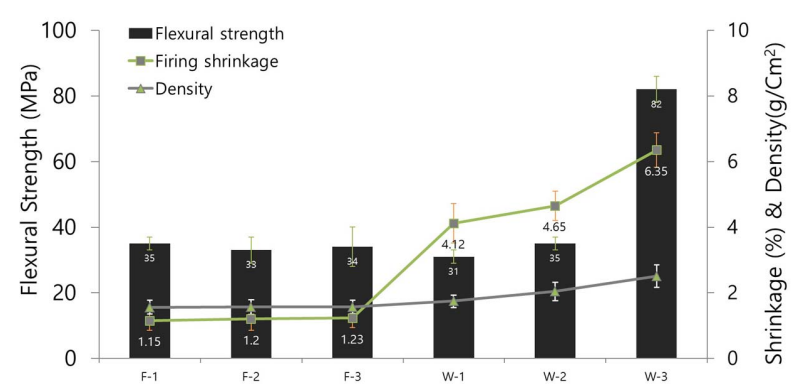

Fig. 15. Flexural strength, density and shrinkage rate of ceramic bodies with addition of feldspar \& wollastonite fired at $1200^{\circ} \mathrm{C}$

Such pores are considered to cause the low strengths of the sintered body with the addition of feldspar, as observed previously. Fig. 14 shows a graph exhibiting the fraction ratios for anorthite phase and quartz phase observed as the main phase and the second phase, respectively, in the XRD patterns per formulation.

In the formulation with the addition of feldspar, the main phase is quartz phase, whose fraction ratio remains at less than $100 \%$, and is slightly increased upon $50 \%$ addition. However, in the formulation with the addition of wollastonite, anorthite is observed as the main phase starting with $30 \%$ addition, and the fraction ratio isobserved to be greatly increased in the formulation with $50 \%$ addition. Fig. 15 shows a graph integrating property values as a function of the incorporated amounts of sintering aids in the body sintered at $1200^{\circ} \mathrm{C}$. While low shrinkage rates were observed in the specimens with feldspar employed as a sintering aid, conforming to the purpose of the present study, lower strength values were observed in comparison with those for commercial materials, disabling the use. While somewhat higher shrinkage rates were observed in the specimens with wollastonite employed as a sintering aid as compared with those for the specimens with addition of feldspar, the specimen containing $50 \%$ wollastonite has a high strength value exceeding that of a commercial material. Therefore, the material with the addition of $50 \%$ wollastonite as a sintering aid realized sufficient densification at $1200^{\circ} \mathrm{C}$, indicating that manufacturing a sintered ceramic body retaining a low 
shrinkage rate in a range of $6 \%$ was possible while material properties on the level of those of commercial materials were secured.

\section{Conclusions}

In the present study, experiments and analyses were conducted on a material with a structure of anorthite crystal phase having similar properties to those of existing commercial materials while sintering temperatures and shrinkage rates, acting as the major factors in the sintering deformation, were reduced to suppress the deformation of traditional ceramic materials.

Through the present study, Anorthite phase as the major phase and of quartz phase as the second phase were confirmed from the microstructural analysis results as a function of the added amount of wollastonite $\left(\mathrm{CaSiO}_{3}\right)$. As the added amounts of wollastonite were increased, the fraction of Anorthite as the main phase relatively increased as compared with that of quartz phase, and the second phase quartz was almost not observed under the condition of $50 \%$ wollastonite. A low shrinkage rate in a range of $6 \%$ along with a strength of $81 \mathrm{MPa}$ is exhibited at content of $50 \%$ where the anorthite phase is observed as the single main phase. According to the analysis results for micrographs, spherical closed pores are homogeneously distributed, demonstrating that sufficient densification is possible at $1200^{\circ} \mathrm{C}$. Since a sufficiently dense sintered body can be obtained at a temperature $50^{\circ} \mathrm{C}$ lower as compared with traditional ceramic materials having Mullite phase as the major phase, it is expected that the possibility of sintering deformation can be effectively suppressed compared with that for commercial bodies used in the past.

\section{REFERENCES}

1. J. S. Moon, Engineering of Pottery; pp.184-92, DooYangSa, Seoul, 2003.

2. J. G. Lee, Sintering of Ceramics; pp.138-46, Bando publisher, Seoul, 1991.

3. S. Kurama and E. Ozel, "The Influence of Different $\mathrm{CaO}$ Source in the Production of Anorthite Ceramics," Ceram. Int., 35 [2] 827-30 (2009).

4. Y. Kobayashi and E. Kato, "Low-Temperature Fabrication of Anorthite Ceramics," J. Am. Ceram. Soc., 77 [3] 833-34 (1994).

5. V. M. F. Marques, D. U. Tulyaganov, S. Agathopoulos, V. K. Gataullin, G. P. Kothiyal, J. M. F. Ferreira, "Low Temperature Synthesis of Anorthite Based Glass-Ceramics via Sintering and Crystallization of Glass-Powder Compacts," J. Eur. Ceram. Soc., 26 [13] 2503-10 (2006).

6. Y. G. Jung, "Effect of Firing Temperature on Mechanical Property and Contact Damage in Pottery (in Korean)," J. Korean Ceram. Soc., 35 [12] 1343-50 (1998).

7. M. U. Taskiran, N. Demirkol, and A. Capoglu, "A New Porcelainised Stoneware Material Based on Anorthite," J. Eur. Ceram. Soc., 25 [4] 293-300 (2005).

8. S. Wang, X. Q, J. Hu, and X. Tian, "Characterization of Anorthite-Based Porcelain Prepared by Using Wollastonite as a Calcium Source," J. Ceram. Process. Res., 16 [3] 361-65 (2015).

9. M. U. Taskiran, N. Demirkol, and A. Capoglu, "Influence of Mixing/Milling on Sintering and Technological Properties of Anorthite Based Porcelainised Stoneware," Ceram. Int., 32 [3] 325-30 (2006).

10. W.-P. Tai, K. Kimura, and K. Jinnai, "A New Approach to Anorthite Porcelain Bodies Using Nonplastic Raw Materials," J. Eur. Ceram. Soc., 22 [4] 463-70 (2002). 